\title{
ANALYSIS AND CONTROL OF INRUSH CURRENT FOR A 33KV DISTRIBUTION SYSTEM
}

\author{
B. Rajagopal Reddy ${ }^{1}$, Md. Asif ${ }^{2}$, Maanasa Devi Atluri ${ }^{3}$ \\ ${ }^{I}$ Associate Professor, EEE Department, Vardhaman College Engineering, Hyderabad, Telangana, India \\ ${ }^{2}$ Associate Professor, EEE Department, Vardhaman College Engineering, Hyderabad, Telangana, India \\ ${ }^{3}$ Assistant Professor, EEE Department, Vardhaman College Engineering, Hyderabad, Telangana, India
}

\begin{abstract}
Capacitor bank switching involves not only handling capacitive currents, but also the remnant/stored energies of capacitor banks, cables and overhead lines. The interruption of a capacitive current induces dielectric problems for the switching device as well as the connected power system. The high inrush currents can cause damage to the capacitive elements of the capacitors bank and may weld the contacts of the switch together. A computer model that represents a $33 \mathrm{kV}$ distribution system is simulated using PSCAD software for purpose of this study and evaluates the switching currents associated with the switching of shunt capacitor banks. Various methods (use of series reactor, synchronous closing and parallel-break switching) for controlling the inrush currents are studied and a comparative analysis is made. The paper highlights and suggests use of auxiliary breaks as a reliable passive mode of control.
\end{abstract}

Keywords-inrush currents, serier reactor, synchronous closing, parallel-break switching, shunt capacitor banks $* * *$

\section{INTRODUCTION}

Capacitor banks are connected in parallel to the power system in order to counter the inductive effect of the industrial and domestic loads, thereby improving the power factor ${ }^{[1]}$. Fixed capacitor banks supply continues leading power factor and hence have no transient problems ${ }^{[2]}$. Switched capacitor banks are the main study objective as their switching activity results in an occurrence of high magnitude and high frequency current transients. These current transients are stressful for switches, relays and circuit breakers ${ }^{[3]}$. For distribution systems, Vacuum circuit breakers (VCB) are advisable as switches to reduce the effect of transients but are not a permanent solution to depend upon as their soft contacts offers lower chopping currents but suffer contact welding in capacitive switching applications also there is a limitation of rated current and MVAR rating in manufacturing $\mathrm{VCBs}^{[4]}$.

An uncharged capacitor when connected to a supply, offer infinite conductance to flow of charge. The sudden flow of charge is seen as high inrush currents or a current transient of high magnitude. Higher system voltage cause breakdown and bridge the closing inter-electrode gap through an arc (preignition). The product of arc-voltage drop and the high inrush current dissipates huge heat energy, which would cause melting and evaporation of interrupter contact materials ${ }^{[5]}$. The hot contacts with clean and fluid surface weld easily under the influence of contact pressure. On closure and cooling the contacts are inseparable rendering the switch unsuitable for further use. Solutions in the form of circuit breakers contacts exhibiting anti-welding or low probability of welding or reduced weld break force are poor substitute for reliability of the equipment and the power system.

A standard simulation tool PSCAD version 4.2.1 has been used for the study of a three phase distribution system of
$33 \mathrm{kV}$ voltage $\mathrm{e}^{[6]}$. Firstly, the distribution system is designed to have an uncharged capacitor bank of $1670 \mu \mathrm{F}$ per phase which is not connected to the system initially and is considered to be switched $\mathrm{ON}$ at $2 \mathrm{~ms}^{[7]}$. The line inductance of $50 \mu \mathrm{H}$ per phase had been in series with the capacitor bank. $50 \mu \mathrm{H}$ line inductance per phase indicates the line of length around $20 \mathrm{~m}$ owing to the fact that capacitor banks are connected very near to the source. This worst case phenomenon of not controlling the switching activity of the capacitor bank, results in producing high inrush current in each phase, as shown in Fig. 4. It is observed from the graph, that the normal peak current is $14.14 \mathrm{kA}$ but the high frequency peak inrush current is found to be around $150 \mathrm{kA}$ in each phase and the transients lasts for $50 \mathrm{~ms}^{[8]}$. The graphical result has been studied and different approaches are made and designed in the same software to reduce this inrush current magnitude.

\section{AVAILABLE SYSTEMS}

\subsection{Series Reactor}

A current limiting reactor is recommended to be placed in the circuit in series with the capacitor bank. This reactor provides an excellent damping effect and limits the high inrush current. The schematic of this technique is shown in Fig. 1. 


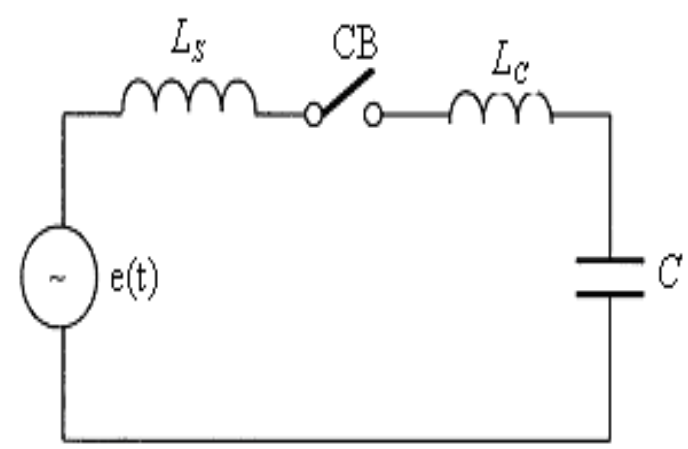

Fig 1: Series reactor schematic diagram.

PSCAD simulation on the similar system of $33 \mathrm{kV}$ source, $1670 \mu \mathrm{F}$ capacitor bank per phase, $50 \mu \mathrm{H}$ line inductance per phase and circuit breaker which closes at $2 \mathrm{~ms}$ is considered. The method is implemented by inserting a series reactor of $5 \mathrm{mH}$ (100 times the line inductance) per phase in the circuit. There is a considerable reduction in instantaneous inrush current from $100 \mathrm{kA}$ to $20 \mathrm{kA}$ in this method. Some conclusions are made on this method after studying the results.

Although this concept is an effective conventional method in controlling inrush currents, there is even a considerable deterioration in system stability and reliability due to possible resonances, caused by the interaction between the added series inductor and system capacitances apart from the main bank. The method also adds to system capital and operational costs. Mechanically, it is a complex design of inserting reactor in the circuit in contrast to its theoretical appearance. This analysis is made from the result shown in Fig. 5.

\subsection{Synchronous Closing}

This is another capacitive switching concept which is very effective in reducing inrush currents and has its own complications in practical installation. This control technique while acceptably understood and implemented for singlephase system, it requires complex modifications with threephase capacitor switches. In order to control the inrush current and over-voltages produced during closure of a circuit breaker, onto a capacitor bank, there could be a zero voltage difference across the contacts of the circuit breaker at the instant when the two contacts of the interrupter meet i.e. the breaker/ switch of each phase should close at zerocrossing of voltage of that phase in order to reduce the peak of inrush current to considerable value.

A PSCAD simulation is done to represent this system for same voltage, capacitor bank and line inductance values of each phase but the difference is made in closing times of the breakers in order that the breaker switches at zero-voltage time of that phase. Breakers of phases A, B and C are timed to close at $0 \mathrm{~ms}, 6.7 \mathrm{~ms}$ and $3.3 \mathrm{~ms}$ respectively. The result can be seen in Fig. 6. It can be observed that the inrush current magnitude is reduced to as low as $30 \mathrm{kA}$ and also the high frequency disturbance settles and the system stabilizes within $40 \mathrm{~ms}$ after capacitor switching.
In practical designing and installation, it is required to control the closing of the breaker/switch, for which a complex algorithm is essential. The algorithm is required to store, utilize and modify all of the available information to accurately predict and ensure a zero-voltage close operation, irrespective of system as well as equipment tolerances. To accomplish closing at or near a voltage zero it is necessary that the breaker/switch consists of a zero detection module, a delay calculation module, artificial intelligence block and a power module. Closing the breaker/switch at or near voltage zero, for aged and worn out circuit breakers, is difficult as closing consistency $> \pm 0.5 \mathrm{mS}$ tend to defeat the very purpose. Considering the fact that a circuit breaker is a highly reliable electro-mechanical device, the composite reliability of the modified system is always lower than the base system, the circuit breaker leads to possibilities of undesired inrush current in this mode as well.

\section{PROPOSED SYSTEM}

After analyzing two methods which are under regular practice, a much latest technique compared to those methods should be introduced this is much more reliable and can be a better solution for the problems being faced in other methods. The technique to be explained in this section is an auxiliary break control in which another circuit breaker is placed in parallel to the main breaker in each phase, as shown in Fig. 2.

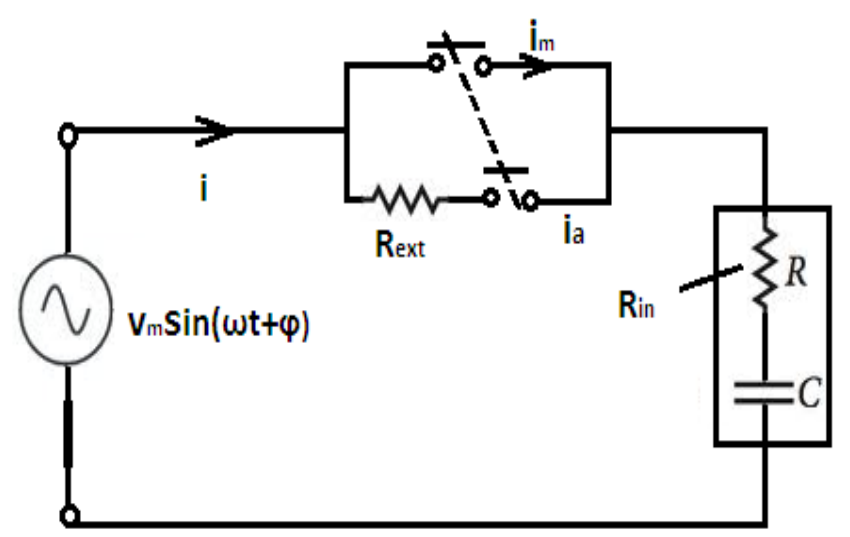

Fig 2: Scheme with parallel-break arrangement for insertion of external resistance.

To explain this concept with better clarity, equation (1) can be referred.

$$
i=e^{-(t / R C)}\left[\begin{array}{c}
\frac{V_{m} \cos \theta}{R}-\frac{\left.\left.V_{m \cos (\theta+\tan (1 / \omega R C}\right)\right)}{\sqrt{\left(R^{2}+(1 / \omega C)^{2}\right)}} \\
+\frac{V_{m} \cos (\omega t+\theta+\tan (1 / \omega R C))}{\sqrt{\left(R^{2}+(1 / \omega C)^{2}\right)}}
\end{array}\right]
$$

Where; $\omega$ is angular frequency and $\theta$ is the phase angle.

Considering a sinusoidal ac input, $\mathrm{V}_{\mathrm{m}} \operatorname{Cos}(\omega \mathrm{t}+\theta)$ Volts to a capacitive load, consisting of a capacitance $\mathrm{C}$ and overall circuit resistance, including internal resistance of the capacitors as $\mathrm{R}$, we find the time dependant current through 
switch at an instant $\mathrm{t}$ after closing of the switch decays exponentially and has a time varying dc component. The peak current at the moment switch closes, depends on the total circuit resistance $\mathrm{R}$.

Hence in order to control the inrush current, an external resistance could be introduced into the system. The sum of both internal and external resistance $\mathrm{R}$ could now be able to reduce the switching transient currents to a much lesser value compared to the system without any switching control. But placing an extra passive element, especially a resistor in the system throughout its operation, would cause losses and extra heat dissipation in the circuit. Therefore, the resistor is connected in series with the auxiliary breaker which closes first, and then by the time inrush currents subsides; main breaker closes to by-pass the resistor. After this the auxiliary breaker opens disconnecting the resistor from the circuit. The timing diagram for main and auxiliary breaks is shown in Fig. 3.

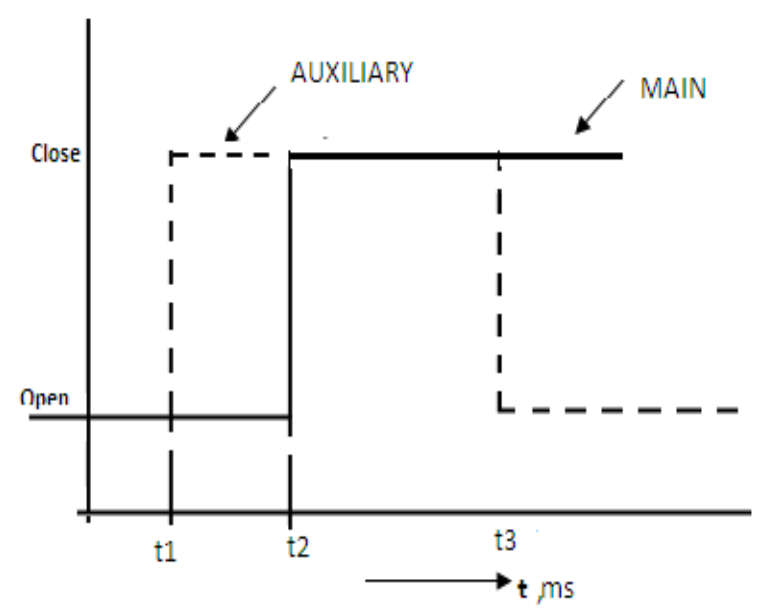

Fig 3: Closing and opening sequences for Main and the Auxiliary contacts.

A PSCAD simulation is done for this method, with design considerations as, $33 \mathrm{kv}$ voltage source, $1670 \mu \mathrm{F}$ capacitor bank per phase, $50 \mu \mathrm{H}$ line inductance per phase and a set of main and auxiliary breakers per phase are taken. The open and close resistances of both main and auxiliary breakers are taken as $10 \mathrm{M} \Omega$ and $100 \mu \Omega$ respectively. Now, referring to Fig.2 and Fig. 3 simultaneously, initially both main and auxiliary breakers are considered to be open. Auxiliary breaker closes first at $2 \mathrm{~ms}(\mathrm{t} 1)$ allowing the inrush current to pass though the resistance connected in series with it. Then main breaker closes at $5 \mathrm{~ms}(\mathrm{t} 2)$ to by-pass the resistor. As the system reaches its near stability condition, auxiliary breaker opens at $10 \mathrm{~ms}$ (t3) disconnecting the resistor from the system. This whole operation is carried out for all three sets of main and auxiliary breakers simultaneously for all phases. The Ohmic value and the thermal rating of the external resistance are selected to meet specification of the capacitor switch. The circuit considered here, is designed for $1 \Omega$ external resistance per phase. The result obtained in this simulation is shown in Fig. 7 through which it can be said that the system stabilizes completely after switching operation within $15 \mathrm{~ms}$ and the peak inrush current value is reduced to around 40kA. Simulations of all the above mentioned methods are carried out for a $50 \mathrm{~Hz}$ system.

\section{COMPARISON OF INRUSH CURRENT CONTROL TECHNIQUES}

A comparative study has been made from all three methods and is mentioned below as table 1 . We can see that the main objective of reducing inrush currents is best fulfilled in synchronous switching method (inrush current reduced from $100 \mathrm{kA}$ to $30 \mathrm{kA}$ ) but the mechanical devices cannot close practically at zero-crossing voltage, hence practically it is not always possible to obtain the vast reduction in peak inrush current. Whereas, there is a considerable reduction in peak inrush current in parallel-break switching also (100kA to $40 \mathrm{kA}$ ) and the same results could be maintained consistently for number of operations.

Installation of extra equipment in each method requires extra time and efforts which are minimum for parallel-break switching method. Installation is difficult for series reactor method and complicated for synchronous closing method. Hence parallel-break switching method can be opted for best results with minimum efforts. Any industries primary consideration for installing new equipment would be the installation cost. This cost is moderate i.e. reasonable for parallel-break switching, while considerably high for other two methods which is again an advantage of the proposed system.

Reliability of the parallel-break switching method is rated as excellent which is its best advantage while the other systems also have reliability ranging from fair to good. From the comparisons made between all three method w.r.t each other for different contexts certifies that the proposed method is much advisable compared to other methods taking all the above mentioned aspects into consideration.

Table -1: Comparison of Inrush Current Control Techniques For The Distribution System Considered.

\begin{tabular}{|l|l|l|l|l|}
\hline $\begin{array}{l}\text { Control } \\
\text { Means }\end{array}$ & $\begin{array}{l}\text { Peak } \\
\text { Inrush } \\
\text { Curre } \\
\text { nt }\end{array}$ & $\begin{array}{l}\text { Installati } \\
\text { on }\end{array}$ & $\begin{array}{l}\text { Relative } \\
\text { Estimat } \\
\text { ed Cost }\end{array}$ & $\begin{array}{l}\text { Estimate } \\
\boldsymbol{d} \\
\text { Reliabili } \\
\text { ty }\end{array}$ \\
\hline None & $150 \mathrm{kA}$ & - & - & - \\
\hline $\begin{array}{l}\text { Series } \\
\text { Reactor } \\
\text { Control }\end{array}$ & $50 \mathrm{kA}$ & Difficult & $\begin{array}{l}\text { Very } \\
\text { High }\end{array}$ & poor \\
\hline $\begin{array}{l}\text { Synchron } \\
\text { ous } \\
\text { Closing }\end{array}$ & $30 \mathrm{kA}$ & Complex & High & Fair \\
\hline $\begin{array}{l}\text { Parallel- } \\
\text { Break } \\
\text { Switching }\end{array}$ & $50 \mathrm{kA}$ & Minimal & $\begin{array}{l}\text { Moderat } \\
\text { e }\end{array}$ & $\begin{array}{l}\text { Excellen } \\
\mathrm{t}\end{array}$ \\
\hline
\end{tabular}




\section{CONCLUSION}

A computer aided design study (simulating most severe conditions) is utilized for a comparative analysis. The study confirms effectiveness of conventional methods and compares the results to the new concept of resistance insertion utilizing auxiliary breaks. Under identical severe conditions, pre-insertion resistors have been demonstrated to reduce over currents to a lower value. Addition of auxiliary interrupter, the external resistance and operating mechanism hardware being proven and passive components would add to system reliability and availability.

Utilities can adopt the new equipment for systems designed for inaccessible locations or remote areas, with constrained inspection schedules. Absence of complex and environment sensitive electronics also relieves utility of extra burden and associated high O\&M costs. The developed arrangements not only enhances life of the interrupters used for such breakers suggests utilizing full capacity of the interrupters reliably. Need for complex electronics and related reliability issues are overcome by selection of field proven hardware for the new equipment. Capacitor banks for various size and capacity can now switched reliably without the fear of contact welding.

\section{REFERENCES}

[1] Greenwood, Electrical Transients in Power Systems, 2nd Edition, John Wiley \& Sons Inc., 1991.

[2] H. W. Dommel, EMTP Theory book, Microtran Power System Analysis Corporation, Vancouver, British Columbia, May 1992.

[3] H. Yan, B.A. Mork, K.K. Mustaphi, "Shunt Capacitor Transient Inrush/Outrush Currents on the 115-kV Bus at Split Rock Substation,” Internal Study, May 1998.

[4] IEEE Standard C37.012-1979 - Application Guide for Capacitance Current Switching for AC High-Voltage Circuit Breakers.

[5] John H. Brunke, "Application of Power Circuit Breakers for Capacitive and Small Inductive Current switching," Application of Power Circuit Breakers, IEEE Tutorial Course 93 EHO 388-9-PWR, 1993.

[6] Modeling and Analysis of System Transients Using Digital Programs, IEEE PES Special Publication TP133-0 (Ch.4 - Modeling Guidelines for Switching Transients).

[7] L. Ganatra, P. Mysore, K. Mustaphi, A. Mulawarman, B.A. Mork, G. Gopakumar, "Application of Reclosing Schemes in the Presence of Capacitor Bank Ringdown," Proceedings of American Power Conference, Chicago, IL, April 1999.

[8] S.J. Kulas," The influence of contact closing velocity on arc duration", Proceedings of the 10th International Conference SAP 2005 on, Switching Arc Phenomena, pp. 106-110, Łódź, Poland, 2005.

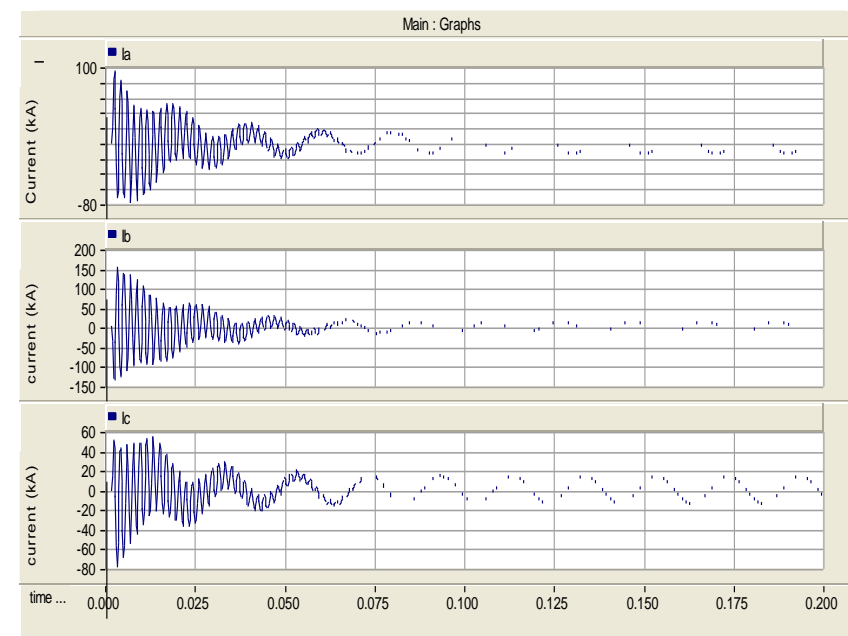

Fig 4: Simulation result without switching control

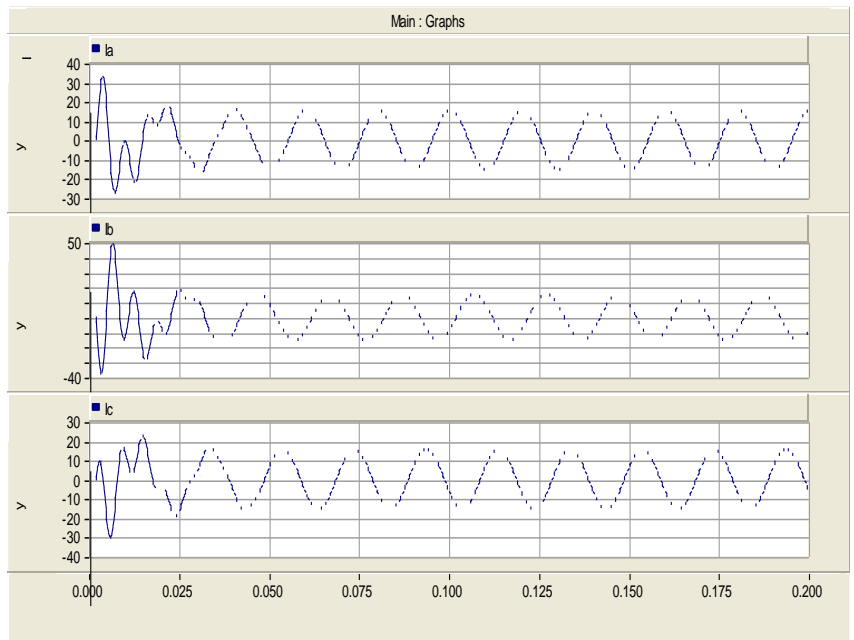

Fig 5: Simulation Result with series reactor

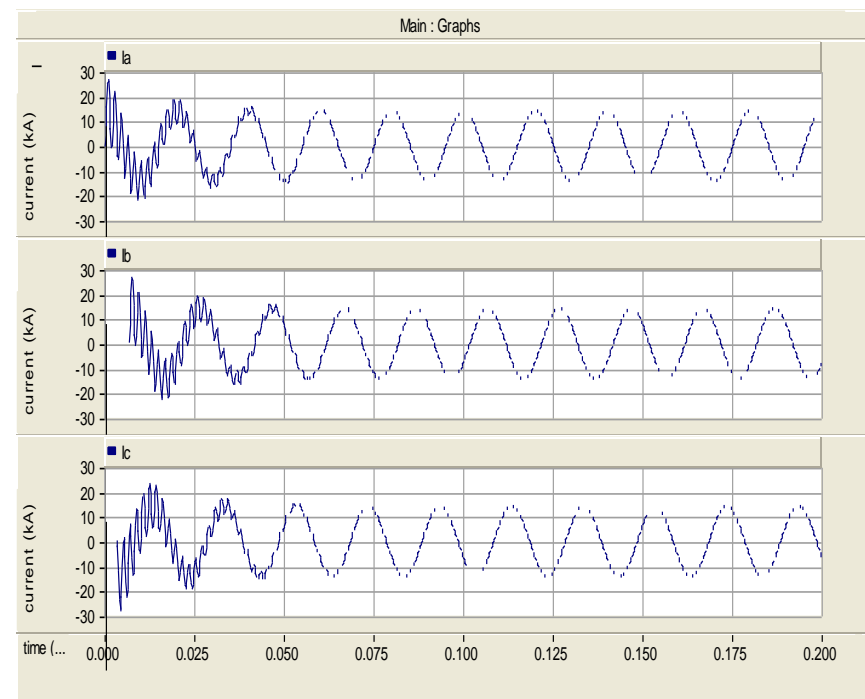

Fig 6 Simulation result for synchronous closing 


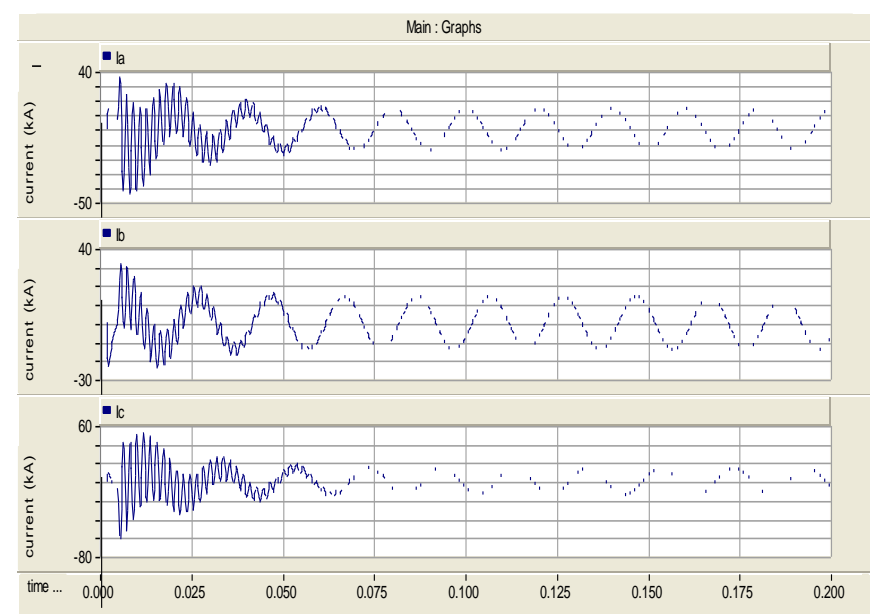

Fig 7: Simulation results for parallel break switching. 